\title{
Empowering the Poor towards Sustainable Development-A Case Study of Self-Help Group Approach in Somaliland
}

\author{
Abdirahman Osman Gaas \\ School of Diplomacy and International Affairs, Euclid University, Bangui, Central African Republic \\ Email: gaas@aogaas.org
}

How to cite this paper: Gaas, A.O. (2019) Empowering the Poor towards Sustainable Development-A Case Study of Self-Help Group Approach in Somaliland. Open Journal of Social Sciences, 7, 26-37. https://doi.org/10.4236/jss.2019.711003

Received: October 1, 2019

Accepted: November 11, 2019

Published: November 14, 2019

Copyright $\odot 2019$ by author(s) and Scientific Research Publishing Inc. This work is licensed under the Creative Commons Attribution International License (CC BY 4.0).

http://creativecommons.org/licenses/by/4.0/

\begin{abstract}
The Self-Help Group Approach (SHGA) was initiated in India in 1985 as a valid concept to eradicate poverty and empower the poor to become self-reliant and energized to overcome the challenges faced. In Somaliland, the SHGA was introduced in 2013 by non-government organizations (NGOs). The approach aims at mobilizing women from disadvantaged communities to empower themselves in social, economic, and political involvement. At present, more than 23,000 women are part of this particular initiative, with the creation of more than 18,000 small businesses funded from the group's savings. This paper examines how this community-led development movement contributes to achieving sustainable development and inclusive economic growth. The study used a qualitative approach, reviewed progress reports, case studies, and external reflections made from SHGA for the last five years, and interviewed direct beneficiaries in cross-checking the responses, and reports read. The findings revealed that the SHGA empowered its members socially and economically through building communities of interdependence and mutual trust that created a social safety net and supported the economic processes through loans, savings, and possible investments among the SHGA members. Finally, the study gave relevant recommendations from the macro-external factors and its internal systems on improving sustainable community-driven and owned development appliances.
\end{abstract}

\section{Keywords}

Empowerment, Self-Help Group, Mudarabah-Musharaka, Sustainable Development

\section{Introduction}

The term "empowerment" refers to any expansion of assets and capabilities of 
poor and vulnerable people to participate in, negotiate with, influence, control, and hold accountable institutions that affect their lives. A self-help group (SHG), also known as "people's institution", is a rights-based approach, which views poverty as a denial of rights and poverty alleviation programs as a process of reclaiming one's rights [1]. This model places equal emphasis on the areas of economic, social, and political empowerment by establishing a people's institution that provides an environment of trust and cooperation, in which people come to realize that they can help themselves achieve their goal. This model has two foundational beliefs 1) Every human being has tremendous potential, which can be unleashed if the right environment is provided; 2) The poor are voiceless, powerless, and vulnerable, but they can gain incredible strength if they are brought together as a homogenous collective.

The concept of SHG first emerged in India in 1985 as a microcredit system, encompassing around 15 - 20 homogenous members and affinity relationships, showing strong relationships between them and several other groups. The Government of India recognized the SHG approach as an essential component to mitigate poverty and, thus, it was included in every annual plan of the government. In 2000/01, several vital steps were taken by the National Bank for Agriculture and Rural Development of India, the Reserve Bank of India, and charity organizations [2].

The approach has implemented in many African countries, including Ethiopia. In 2013, since Ethiopia has been implementing SHGA for ten years, several selected NGOs from Somaliland visited SHG women in Ethiopia to assess whether the approach would be successful in replicating into Somaliland. Upon their return, the visitors decided to introduce the approach in two regions named Marodijeh and Togdher. Although at the early days of the inception phase the process had faced a lot of challenges, documents reviewed revealed that it has now helped to create to establish a strong cohesion among the members of the SHG and all members have created several small businesses, contributing to poverty reduction by fueling community-driven development, also contributing to achieve goal one of the sustainable development goals, as UN 2015 target 1.4 states: "By 2030, build the resilience of the poor and those in vulnerable situations and reduce their exposure and vulnerability to climate-related extreme events and other economic, social and environmental shocks and disasters". As this model is new to the global and in Somaliland particularly, this paper aims to explain how this approach works and it also aims to examine whether an intervention without external financial support that is materialist in nature can lead to a sustainable development, to reshape the mindset of development workers who look at the needs and expectations of the poor, instead of focusing on unleashing their potentiality.

\section{Methodology}

This study began with a desk-based review of existing secondary literature and 
periodic reports by the NGOs implementing the approach. This review included the official reports, relevant governmental statements, published and unpublished studies, and documentary sources. The SHGs in Somaliland operate in two cities, Hargeisa and Burao. This study interviewed 15 members ${ }^{1}$ who had joined the SHGA in 2014; to verify the achievements reported. The interviewed respondents provided contrasting examples of the role of self-help. As Yin (2014) has pointed out, a research design that incorporates in-depth explanations, such as why and how a specific phenomenon occurs, offers the opportunity to explain critical mediating factors [3]. This study focuses on understanding the different roles that SHGs plays in empowering the poor by building sustainable businesses, access to financing, and inclusive growth. As well as the study traced out the approaches achievements in Somaliland for the last five years. Furthermore, the annual reports of the program from 2014 to 2018 generated by the nongovernmental organizations implementing the approach that study focuses.

The interview focused on three main aspects, which are listed below as follows: 1) profile of respondents; 2) group functioning characteristics, such as group interaction, cooperation, interpersonal trust, motivation, cohesiveness, decision-making, and common goal achievements; 3) facilitating and hindering factors of effective group work. A sample of 15 respondents was targeted. However, only 13 questionnaires were retrieved, giving the researcher a confidence level of $86.7 \%(13 / 15 \times 100)$.

\section{Maintaining the Integrity of the Specifications}

The template is used to format your paper and style the text. All margins, column widths, line spaces, and text fonts are prescribed; please do not alter them. You may note peculiarities. For example, the head margin in this template measures proportionately more than is customary. This measurement and others are deliberate, using specifications that anticipate your paper as one part of the entire journals, and not as an independent document. Please do not revise any of the current designations.

\section{Poverty and Microfinance Situation in Somaliland}

Somaliland is a poor-income country with a gross domestic product (GDP) per capita of $\$ 348$, thereby ranking as the $4^{\text {th }}$ lowest-income country in the world, only ahead of Burundi, DR Congo, and Malawi, with more than 1 in 4 people in urban Somaliland and more than 1 in 3 people in rural Somaliland living in poverty [4]. People living in poverty need perpetual access to financial services from commercial banks. However, only a few financial service providers are available in the market to provide limited loans and investments, particularly for low-income and small-scale entrepreneurs. Products offered by service providers

${ }^{1}$ Each member representing one group of 20 members, so the interview covered 200 member's status to be good sample of the approach population. 
include the use of Murabaha ${ }^{2}$, Mudaraba $^{3}$, and Qardul Hassan ${ }^{4}$ as instruments to finance their clients [5]. Furthermore, there is no government policy about poverty alleviation and community-driven programs to empower the poor. In this context, the majority of the poor are not eligible to take loans from commercial banks and, thus, microfinance institutions have been established to enable the poor to meet their needs [6]. Microfinance is the provision of a broad range of financial services, such as deposits, loans, payment services, money transfers, and insurance products, to the poor and low-income households for their microenterprises and small businesses, aiming to enable them to increase their income levels and improve their living standards.

\section{The Concept of Self-Help Group}

The SHG is a method of organizing the poor and the marginalized people to come together to solve their problems. The concept of SHG that emerged in India in 1985 with the principles of accompanied mutual help can be a powerful vehicle for the poor in terms of socio-economic development. The poor people need not only credit support but also savings and other services. The poor are capable of saving and being banked on, and SHGs, as clients, result in more extensive outreach to lower transaction costs and much lower risk costs for banks. A collective fund can be created by regularly contributing small savings. A flexible democratic system of working needs to put in place. Loans are mainly provided on trust with bare documentation and without any security. Small, frequent loans are provided for a short duration. Defaults are rare, mainly due to group pressure. There should be periodic meetings with non-traditional savings [7].

\subsection{Levels of SHGA}

According to Kindernothilfe documents, SHG is a holistic approach, which, when implemented, according to the principles, leads to the social, economic, and political empowerment of an individual, a community, and beyond. The approach has three levels; each level involves a specific level of tasks that complement one another (Figure 1).

\subsubsection{Self Help Groups (SHGs)}

This is the first level of the approach that is formed with $15-20$ homogeneous members ${ }^{5}$ from neighboring communities selected with a competitive process by using Participatory Rural Appraisal (PRA) and wealth ranking tools. With a

\footnotetext{
${ }^{2}$ Murabaha is not an interest-bearing loan, which is considered riba (or excess). Murabaha is an acceptable form of credit sale under Sharia.

3"Mudarabah" is a special kind of partnership where one partner gives money to another for investing it in a commercial enterprise.

${ }^{4}$ Qardul Hassan: “This is a loan extended on a goodwill basis, and the debtor is only required to repay the amount borrowed. However, the debtor may, at his or her discretion, pay an extra amount beyond the principal amount of the loan".

${ }^{5}$ Members should be homogeneous in terms of gender and wealth ranking; not mix of gender.
} 


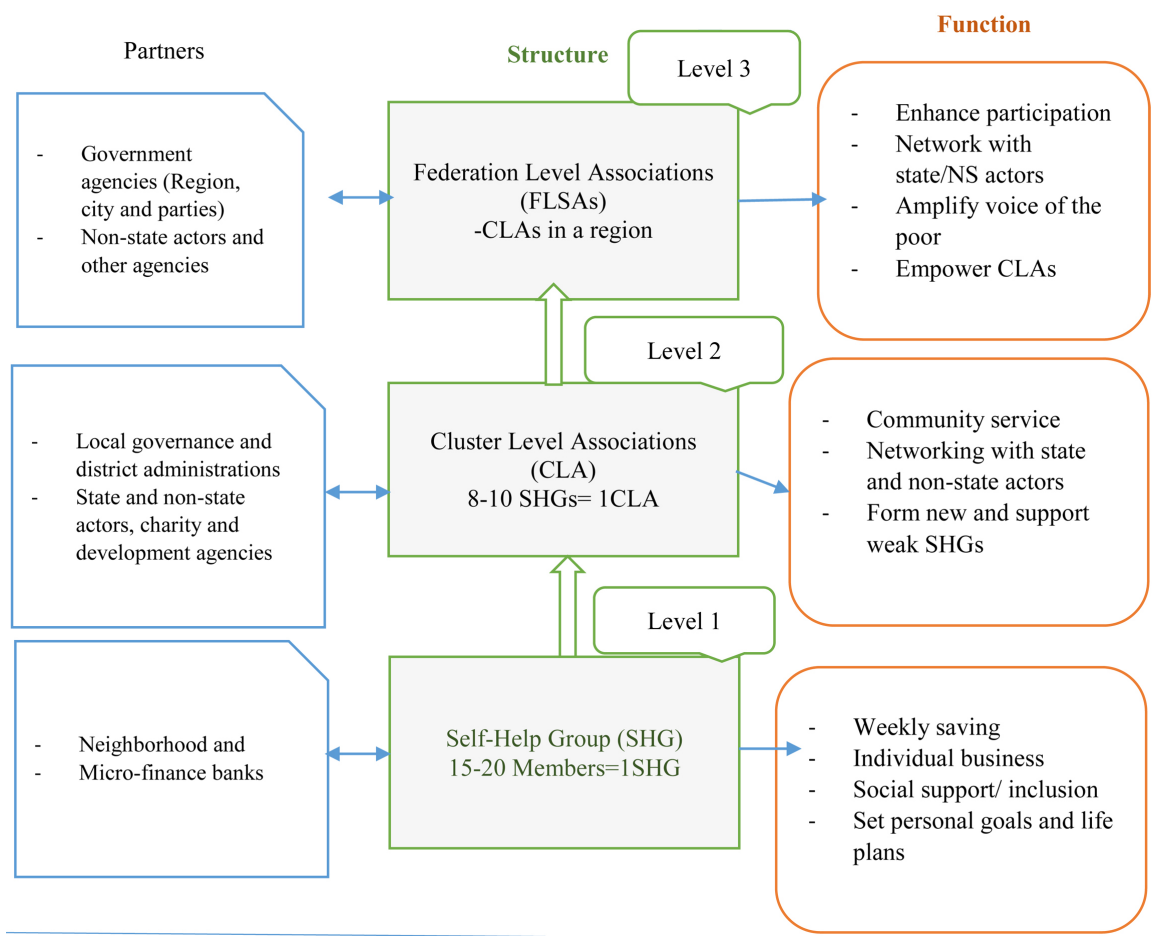

Figure 1. This figure depicting the three levels of the SHGA, functions and partnership.

rotational leadership ${ }^{6}$. The functions of this level (SHG) include weekly meetings with regular savings, saving amount depends on group judgment; some groups start with 5000 Somaliland Shillings equal to (0.7 USD) per week per person, and others save up to 8000 Somaliland Shillings (1 USD). Empower individuals by encouraging them to come up with business plans, which will validate by the rest of the group and taking loans from the group's savings. During meetings, members discuss and decide standard rules, share their problems, and give each other advice, leading to the development of care and concern for one another. Members set individual/personal goals and group goals to change aspects of their lives and environment.

\subsubsection{Cluster-Level Association (CLA)}

The CLA is the second level of the approach structure; it consists of 20 members selected by 10 SHGs, meaning each CLA represents 200 families. They work on community interest with the slogan of "we can do it". They have structure and sub-committees with rotational leadership, which depends on the group terms. Their main function is to mobilize resources to meet the needs of the community from the private sector, government, and non-government sources. Each CLA receives subscription fees from its SHG groups ${ }^{7}$ for the basic running costs. Furthermore, they work to support their groups to voice the community challenges such as education and schooling, health and sanitation, food, and other needs of ${ }^{6}$ Every week a member hosts the group meeting, so in each meeting they decide who will host the next meeting and who will lead.

${ }^{7}$ SHGs Monthly subscription fees to the CLA has no fixed rate, but its in the range of 5 to 10 USD per SHG. 
the respective community.

\subsubsection{Federation}

The third level of the approach is expected to form a visible and sustainable people's institution. The CLAs in each region form this body by electing an executive committee of about 15 - 20 members. In the long term, this institution should be able to stand independently. A federation advocates for the rights of women, and it jointly claims their entitlements by utilizing the strength of numbers that it represents by playing the role of an effective bridge between the poor people and the State. A federation can contribute to peace, inclusivity, security, and justice by raising its voice against injustices and seeking good governance and accountability from the responsible authorities and decision-makers. A Federation obtains a subscription from the CLAs, and it raises resources from external donors to execute the advocacy work for the poor people.

\subsection{The Evolution of the Approach in Somaliland}

Several SHG approaches are existing in Somaliland implementing by nongovernmental organizations with different methodologies. This selected SHG approach was commenced in Somaliland in September 2013 by 11 local organizations named "SHG promoters" in two regions (Marodijeh and Togdher). NAFIS NETWORK had been selected to lead the process of the approach with the financial and technical support from the Kindernothilfe-German-based organization.

\section{Impact of SHG on Somaliland}

According to NAFIS 2018 annual report, from the inception period, the approach registered 23,106 members across 1160 groups and 105 CLAs, with 12,9972 children benefitting from the establishment of 18,656 small businesses [8]. During the fieldwork ${ }^{9}$, when asked whether their groups have a common goal, $92.3 \%$ of respondents said "yes", while $7.7 \%$ said "no". Thus, this suggests that SHGs have a common goal that brings members together to combine efforts to pursue their goals. Such as the sense of belonging, overcoming isolation, having plans in life, looking into the future positively, having ambitions to change their lives and the lives of their children, this is vital for members of a group to share such common goals, as it cultivates concerted efforts.

\subsection{Savings and Financial Decision-Making}

Documents reviewed revealed that Members of SHGs were empowered and provided knowledge in terms of savings and financial decision-making by the community facilitators hired by the promoting organizations. No external seed money given to the group, they make weekly savings. After the first two to three ${ }^{8}$ SHG Promoters: ADO, BVO, CCBRS, CANDLELIGHT, GAVO, SAWRAG, SOYDAVO, TASCO, WORDA, SAWDA and WAAPO.

${ }^{9}$ To validate what I have read from the reports, I interviewed 15 women from different groups. 
months, saving becomes a pool of funds to be borrowed by the members. The approach developed their attitude of saving, which was not part of their financial behavior before the implementation of the SHG approach. From the time this approach introduced, an ever-increasing number of women have been taking charge of financial planning for their families. Women also continue to heavily contribute to household income, with most of them being the primary breadwinners of their families.

This saving culture has changed the behavior of women dramatically because they now prefer investing their claims in various savings avenues. They now prefer to invest in child education and health, personal safety, and family consumption. Their spending behavior has equally improved because of the knowledge have acquired regarding expenditure and spending, which are factors that influence savings and financial investments. Every member of the group is eligible to bring business ideas and plans; then, the other members will determine the business idea that they are investing this time in terms of relevance, sustainability, and the need according to the area.

During the fieldwork, when respondents were asked whether they record their savings for their businesses, $92.3 \%$ of them answered positively while the remaining $7.7 \%$ said they do not. Through the training organized for these women, especially in terms of business skills development, most of them have learned the art of bookkeeping. Bookkeeping is essential to these women, as it enables them to understand expenses vis-à-vis income, which, in turn, aids them to separate capital from profit.

\subsection{Access to Credit}

It is common in low-income countries that poor women can limitedly access to credit. Conversely, the SHG approach has created smooth financial access instruments, allowing members to borrow funds from the group to start a business. All the interviewed members got loans from the group fund and established their business. Concerning whether the respondents benefit from SHGs, $100 \%$ said "yes". This indicated that the SHG approach is gaining ground among marginalized women, as it is rekindling their hopes to a large extent. This group fund is exempt from bureaucratic bottlenecks that observed when approaching commercial banks, friends, or even microfinance institutions. This approach has also encouraged banks to offer financial access to poor women with minimal conditions, unlike in the case of their regular clients, as these women disciplined with clear targets.

\subsection{Mudarabah-Musharakah}

Musharakah-Mudarabah is a joint enterprise or partnership structure in Islamic finance in which partners agreed to share the profits and losses, while the entrepreneur has some in the capital but agreed to share. Since Islamic law does not permit profiting from the interest in lending, musharaka allows for the financier 
to achieve a return in the form of a portion of the actual profits earned according to a predetermined ratio [9].

To smooth the implementation of the approach, the promoting organizations consulted with religious leaders to come up with an acceptable approach in Islam that can apply when the members are taking loans from the group fund. Then the religious leaders have appreciated the approach and introduced the mudarabah-musharaka system ${ }^{10}$. In practical, when a member taking a loan from the group, they use the term "invest" then the group own the money while the lender works out and share the profit as per their agreement, then pay back the money and continue the business [10].

\subsection{Employment}

SHGs have allowed women to save and borrow funds to start small-scale businesses, so far more than 18560 (eighteen thousand five hundred sixty) businesses were created; although there is no well-documented statistics it is estimated about 20,000 people employed; mostly are women since women set idle, as they were unemployed [11]. However, the increase of self-employment in comparison to formal employment among women members of SHGs is visible since women are now owing to the number of businesses they are involved in.

\subsection{Family/Household Income}

With respect to why women have joined SHGs, $76.9 \%$ of the respondents indicated that they joined to get loans to invest in various business opportunities available in their respective areas, $7.7 \%$ joined to develop their business investment skills, and the remaining $15.4 \%$ joined an SHG to get empowered, as when women work together and operate businesses, what used to be a burden at individual level ceases to be one at the group level.

The daily involvement of women in small-scale businesses due to loans from SHGs has boosted household income, which, in turn, has raised the standards of living of these women and their families. Furthermore, some women have ended up becoming the sole breadwinners of their households, especially in women-led families. According to NAFIS 2018 report; approximately 80,000 children now have access to education because their mothers have an income, and good health has significantly increased.

\subsection{Participation in Community Committees and Municipalities}

Women are under-representation at any level of governance and decision-making tables, which results in a democratic deficit. Through the SHG approach, women have become aware of the governance structures within their localities. They now discern where to go to seek assistance or report social challenges. As documents reviewed revealed, the women belonging to an SHG are important actors

${ }^{10}$ Musharakah-mudarabah is capital provided by each party involved. Capital is provided by the investor only, while the other party becomes the manager, without putting in any money. The similarity between Musharakah and Mudarabah is both parties share the profit with pre-agreed ratios. 
in district and city council movements, as the only organized and share a common agenda group. In two districts of Burao city (October and M.Ali), SHG members become governors.

\subsection{Self-Confidence and Gender-Based Violence}

Before joining SHGs, women did not understand what it takes to be a part of a group. The formation of SHGs has created a platform where women can test their leadership skills, through their meetings and discussions on issues relating to welfare, they have developed. It is during these discussions that women realize their leadership skills, giving them the confidence to take part in local authority elections, as they can now better express themselves. Concerning family acceptance of respondents being a member of an SHG, all respondents reported that their families endorse their participation. This acceptance can be attributed to the benefits that these groups entail for their members' households.

Most family conflicts, especially those involving spouses, arise due to limited financial resources. In the poor areas, many husbands see their wives as a burden, but with economically empowered women, they feel less burdened. The SHG approach has reported that many family conflicts have now been sorted, as the neighborhood is now connected and aware of their challenges.

\subsection{Government Commitment}

The Government of Somaliland has shown its commitment to SHGs on several occasions; for example, during the commemoration day of SHG in 2016 and again in 2018, the vice president demonstrated his commitment as he said "government is very impressed for the first time, now I'm committing to implement a study about how this approach can be mainstreamed into the public agenda and development projects without affecting the standards and the best practice of the approach" [12]. This assurance gave strong sense to the SHG members, and the interviewed individuals mentioned that promise of recognizing the SHG approach as a working method.

\section{Major Challenges in Implementing the SHG Approach}

Community expectations from external handouts such as donation funds are high; if some organizations offer something, it always destroys the formed groups. Similarly, although many members have realized the importance of the SHG approach, new members always have high expectations of getting funding from external donors and little confidence in the approach. Training facilities for the members of SHGs in specific areas of product selection, quality of products, production techniques, managerial ability, packing, and other technical knowledge such as leadership is not adequate.

In certain SHGs, the return from the business is not adequately invested in units, as the funds are diverted toward other personal and domestic purposes, such as marriage and construction of a house, indicating weak financial man- 
agement. Most financial institutions do not take SHGs seriously while providing finance and other bits of help. Furthermore, although the vice president committed to collaborating with the approach, the Line Ministry's officers are not fully co-operative with the members, which hampers to achieve the objective of the SHG at the national level.

Moreover, the government, apart from the verbal promise made by the Vice President, has not made any practical commitment to realize to mainstream this approach into the national development strategies and the national budget.

\section{Conclusions}

The SHG approach is used by various actors to address unemployment reduction, economic development, and the social well-being of communities to strengthen low-income and vulnerable people. The primary concept of the SHG is relatively straightforward: establishing a voluntary (financial) saving association comprising a small homogenous group of people in a local community. However, the reality of how the SHG approach works and what this implementation entails varies significantly among organizations.

Concerning social development, the findings of this study indicated that the SHG approach empowers its members socially, through building communities of interdependence and mutual trust. It has created a social safety net that supports the economic ventures of its members. As the members do not know each other before joining the group, the development of trust is seen as a significant asset in the first place.

For the safety net development, the approach has two different levels, 1) Members get to know each other, and then 2) acquire knowledge about each other's social and economic situation, as well as each other's behavior. Furthermore, SHGs have a gendered impact. First, SHG meetings extend the movement radius of many women. Most women who reached out to the SHGs have left their homes due to unemployment, and those belonging to poor recourse communities, mainly stay at home to look after their children and the households. The group has become a knowledge hub for many members where they can bring their questions and receive support from others who might have the necessary expertise that they still lack. This level of groups further extends to the perception of the members of SHGs as a place to gain the courage to make changes in their surroundings.

For women's economic development, the SHG approach can lead to mid or long-term economic empowerment of its members. The economic processes of loans, savings, and possible investments decided within the groups during their regular meetings, and members find this to be a fair and transparent process. The ability of SHG members to empower the poor segments of Somaliland's society is unique in the sense that these groups aid in strengthening interdependent communities of trust, which can also be converted into collateral communities. 
At the community level, to win community acceptance of women's participation in SHGs, the approach targets community gatekeepers to convince them that women should also be part of their family's interest. It should be distinguished that without changing the attitudes of men, it is difficult to change the attitudes of the rest of the family and the community. Therefore, this approach has attracted the attention of many, such as development agencies, banks, international organizations, government institutions, and social activists, but without getting a common approach and future shared prosperity, the movement will not yield properly.

\section{Recommendations}

Based on the conclusions drawn from the desk review, individual interviews, and author's analysis on the status quo; then the paper suggests the following recommendations:

Skills development amongst SHGA members must be based on an actual local market assessment of the needs SHGs to take careful preparation of suitable business plans to minimize any negative experience that they might have had with SHGs.

NGOs and other actors implementing this approach can play an essential role in transforming the poor to be potential entrepreneurs by providing basic education, motivation, and proper guidelines. To be realized, there should be general guidelines and proper coordination to align with national development plans and strategies.

The self-help group approach can be used as a tool to fruitfully integrate internally displaced peoples (IDPs) and returnees into host communities. This often necessitates a more prolonged, planned community mobilization and engagement.

\section{Recommendations for Further Research}

Future research should focus on the following aspects:

Establishment and functionality of SHGs for men in the global and in Somaliland.

Hurdles that stand in the way of SHG sustainability and how using Mudaraba-Musharaka financial method is implementable and appropriate to the approach.

\section{Acknowledgements}

The Authorship of this paper would not have been possible without the spirit of the SORADI Institute which enabled the practice of the social research methodology. Grateful to the Dr. Mohamed Fadal for the mentorship and the organizations and community respondents who generously participated in this study. The author also thanks to the colleagues and peer reviewers for their contribution to refining the paper. 


\section{Conflicts of Interest}

The author declares no conflicts of interest regarding the publication of this paper.

\section{Biography}

Abdirahman Osman Gaas is a Ph.D. candidate in Sustainable Development and Diplomacy at EUCLID University, Bangui, Central African Republic. He earned in 2014 Master of Arts in Development Studies from Kampala University, Uganda. He holds a certificate of Excellence in research and a Certificate in Leadership. He has published the following research papers and books: "challenges and breakthrough for Horn of African Regional Integration" and "Impact Assessment of Recurrent Droughts on Agricultural and Pastoral Communities in Somaliland" and Sustainable development book.

\section{References}

[1] KNH (2016) The Self-Help Group Approach. Kindernothilfe.

[2] Fernandez, A.P. (2007) History and Spread of the Self-Help Affinity Group Movement in India/The Role Played by IFAD.

[3] Yin, R.K. (2014) Case Study Research Design and Methods.

[4] World Bank (2015) Somaliland: Poverty Profile and Overview of Living Conditions. Poverty Global Practice.

[5] ILO (2013) Finance Sector Diagnostic Study. International Labor Organization, Hargeisa.

[6] Singh, P. (2019) Impact Ranking of Microfinance Institution Empirical Studies in India. International Journal of Indian Culture and Business Management, 19, 189-210. https://doi.org/10.1504/IJICBM.2019.10020433

[7] Seibel, H.D. (2005) SHG Banking in India: The Evolution of Rural Financial Innovation. University of Cologne, Development Research Centre, Cologne.

[8] NAFIS (2018) Annual Report. Somaliland, Hargeisa.

[9] Salehuddin, S. (2016) Musharakah Tijarah Cross-Border Financing: Concept, Structure and Salient Features. International Journal of Islamic Economics and Finance Studies, 2, 1-26.

[10] NAFIS (2016) Annual Report. Somaliland, Hargeisa.

[11] NAFIS (2017) Danwadaag Journal. Somaliland, Hargeisa.

[12] Togdheer (2018) Madaxweyne Ku Xigeenka JSL Oo Ka Qaybgalay Xaflada Bandhiga Ururada Dan-Wadaag. Somaliland, Hargeisa. http://togdheernews.com 